\title{
ETAPAS E CUSTOS DOS PROJETOS DE MECANISMO DE DESENVOLVIMENTO LIMPO - MDL
}

Sidney Araujo Cordeiro - Doutorando em Ciência Florestal - Universidade Federal de Viçosa, sidney.cordeiro@ufv.br.Celso Coelho de Souza-Mestre em Ciência Florestal-Universidade Federal de Viçosa, Celso.souza@ufv.br. Zaíra M. S. H. Mendoza-Professora da Universidade Federal de Mato Grosso,

Zaíra@ufmt.br. Márcio Lopes da Silva - Professor do Departamento de Engenharia Florestal Universidade Federal de Viçosa, marlosil@ufv.br

\section{RESUMO}

O Mecanismo de Desenvolvimento Limpo (MDL) é um dos instrumentos de flexibilização estabelecidos pelo Protocolo de Quioto com o objetivo de reduzir a emissão de gases de efeito estufa. As negociações são feitas utilizando-se projetos que são executados entre as partes interessadas. Os custos desses projetos estão em todas as etapas do processo variando em função da finalidade e porte. Eles devem cumprir basicamente sete etapas definidas de acordo com normas padronizadas.

Palavras-chave: Projetos de MDL, etapas, custos.

\section{STAGES AND CUST FOR PROJECTS OF CLEAN DEVELOPMENT MECHANISM - CDM}

\begin{abstract}
The Clean Development Mechanism (CDM) is one of the more important instruments, established by the Kyoto Protocol to reduce the emission of greenhouse gases effect. The negotiations were made using the projects that were executed by the interested people. The costs of these projects are presented in all the stages of the process varying as function of the purpose and size. They should be elaborated basically in seven stages, defined in accordance with standardized norms.
\end{abstract}

Key-words: Projects of CDM, stages, cost.

\section{INTRODUÇÃO}

O Mecanismo de Desenvolvimento Limpo (MDL) é um dos instrumentos de flexibilização estabelecidos pelo Protocolo de Quioto com o objetivo de facilitar o alcance das metas de redução de emissão de gases de efeito estufa definidas para os países que o ratificaram. Em síntese, a proposta do MDL (descrita no Artigo 12 do Protocolo) consiste em que cada tonelada de $\mathrm{CO}_{2}$ equivalente $\left(\mathrm{tCO}_{2} \mathrm{e}\right)$ que deixar de ser emitida ou for retirada da atmosfera por um país em desenvolvimento poderá ser negociada no mercado mundial, criando novo atrativo para a redução das emissões globais (MOREIRA, 2008).

O Protocolo determina que os países do Anexo I (países desenvolvidos com metas de redução de emissões) devem fixar suas metas para redução de gases de efeito estufa junto aos principais emissores dentro de seus territórios, de acordo com a meta que lhes foi atribuída pelo Protocolo e, posteriormente, distribuída pelo governo local por meio de seu plano nacional de alocação de emissões. Com a introdução do MDL, as empresas que não conseguirem (ou não desejarem) diminuir suas emissões poderão 
comprar Reduções Certificadas de Emissões (RCE's) em países em desenvolvimento (que tenham gerado projetos redutores de emissão de gases de efeito estufa - GEE) e usar esses certificados para cumprir suas obrigações, ainda que o uso desse mecanismo esteja limitado a uma parcela de seus compromissos de redução (MENEGUELLO, 2007).

Os países em desenvolvimento, por sua vez, devem utilizar o MDL para promover seu desenvolvimento sustentável, além de se beneficiarem do ingresso de divisas por conta das vendas de RCE's para os países desenvolvidos.

Existem critérios para que um projeto seja elegível como um "Projeto de MDL". São eles:

- Participação voluntária;

- contribuição com o objetivo final da Conferência das Partes;

- geração de adicionalidade;

- contribuição para o desenvolvimento sustentável do país no qual venha a ser implementado;

- a atividade do projeto deve ser capaz de demonstrar benefícios reais, mensuráveis e de longo prazo, relacionados com a mitigação da mudança do clima;

- aprovação do país onde as propostas forem implementadas;

- existência de valores mínimos a serem respeitados.

Por outro lado, alguns tipos de projetos são inelegíveis no âmbito do MDL. São eles:

- Conservação florestal e qualquer mudança no uso da terra que não seja florestamento ou reflorestamento;

- energia nuclear;

- geração não-sustentável de energia proveniente de biomassa.

Dentre os mercados para o comércio de créditos de carbono, podemos citar a "Bolsa do Clima de Chicago" (Chicago Climate Exchange - $(C X)$, o Mercado Europeu de Emissões (Europe Union's Emissions Trading Scheme EU ETS) e a iniciativa em estudo do "Mercado Brasileiro de Redução de Emissões (MBRE)" (CEPEA, 2006).
Os projetos que se habilitam à condição de projeto de MDL devem cumprir uma série de procedimentos até receber a chancela da ONU, por intermédio do Conselho Executivo do MDL, instância máxima de avaliação de projetos de MDL.

Um projeto de MDL deve percorrer as seguintes etapas para ser reconhecido no Protocolo de Quioto e gerar créditos, isto é, redução certificada de emissões:

- o proponente do projeto (uma empresa) deve elaborar o Documento de Concepção do Projeto (DCP);

- a Entidade Operacional Designada deve validar a metodologia utilizada no DCP;

- a Autoridade Nacional Designada deve aprovar o projeto proposto;

- o projeto deve ser, em seguida, registrado no Conselho Executivo do MDL;

- o proponente do projeto deve desempenhar a atividade de monitoramento;

- a Entidade Operacional Designada realiza a verificação e a certificação da redução de emissões resultante do projeto;

- o Conselho Executivo do MDL emite a redução certificada de emissão (RCE).

Estas etapas serão tratadas com maior nível de detalhamento no decorrer deste trabalho.

A implantação de um projeto de MDL, além de diversas etapas, envolve custos que dependem de uma variedade de fatores inerentes ao mesmo. Estes custos também serão tratados no decorrer do trabalho.

O presente trabalho objetiva descrever e caracterizar as principais etapas e os possíveis custos envolvidos na elaboração dos projetos de Mecanismo de Desenvolvimento Limpo (MDL).

\section{METODOLOGIA DE ESTUDO}

Para o levantamento de informações necessárias ao estudo das Etapas e Custos do Mecanismo de Desenvolvimento Limpo, utilizou-se o método de pesquisa rápida, confor- 
me IEL/CNA/SEBRAE (2000). Neste método, as informações empíricas associam-se às informações de fontes secundárias.

As informações e os dados necessários para a realização deste estudo foram obtidos basicamente de material disponível na internet, em "sites" de renome na área de MDL. Cada um dos autores pesquisou sobre determinado assunto dentro do tema central, e, posteriormente, efetivaram-se reuniões onde os conhecimentos adquiridos separadamente foram compartilhados pelos mesmos. Após intensas discussões, o trabalho foi sendo aprimorado através das diversificadas opiniões dos autores, sendo posteriormente escrito sob a forma de artigo.

\section{RESULTADOS}

\section{Conceitos importantes para entendimento do ciclo do MDL}

Os conceitos utilizados neste trabalho estão em conformidade com BVRJ (2007).

\section{Convenção-Quadro das Nações Unidas sobre Mudança do Clima}

Tratado assinado em 1992, no Rio de Janeiro, por ocasião da Conferência das Nações Unidas sobre Meio Ambiente e Desenvolvimento (ECO- 92), que tem como objetivo a estabilização das concentrações de GEEs na atmosfera, de forma a impedir interferência antrópica (produzida pelo homem) perigosa no sistema climático. A convenção estabelece "responsabilidades comuns, porém diferenciadas" aos países participantes (partes). Vem daí o tratamento diferente dado ao Anexo I (documento integrante do Protocolo de Quioto que lista os países desenvolvidos aos quais foram atribuídas metas de redução de emissões) e aos emergentes (BVRJ, 2007).

\section{COP (Conferência das Partes)}

Conferência das Partes (ou seja, dos países signatários da Convenção-Quadro).
Representa o órgão supremo da ConvençãoQuadro das Nações Unidas sobre Mudança do Clima, cabendo-lhe estabelecer as regras para implementar a Convenção. A COP reúne-se, anualmente, desde 1995, em um dos países participantes. A de número 3 (1997) resultou no Protocolo de Quioto.

\section{Documento de Concepção do Projeto (DCP)}

Documento elaborado pelo proponente (empresa) que contém as seguintes informações: descrição geral do projeto; metodologia de linha de base a ser utilizada; prazo do projeto; metodologia e plano de monitoramento; estimativa de emissões de gases de efeito estufa; impactos ambientais do projeto; comentários dos participantes envolvidos; informações sobre fontes de financiamento público de partes do Anexo I (países desenvolvidos listados na Convenção-Quadro das Nações Unidas sobre Mudança do Clima) para o projeto.

\section{Linha de base do projeto de $M D L$}

A linha de base - ou cenário de referência - do projeto de MDL é o nível atual e a evolução das emissões de GEEs que ocorreriam caso o projeto não fosse implantado. Esse cenário será utilizado para o cálculo da redução de emissões (créditos) a serem gerados pelo projeto. A linha de base fundamenta-se em metodologia préaprovada pelo Painel de Metodologia do MDL (grupo formado por cientistas de diversos países que objetiva dar suporte técnico ao Conselho Executivo, analisar e propor recomendações sobre novas metodologias de linha de base e de monitoramento encaminhadas ao Conselho para aprovação no âmbito do MDL).

\section{Conselho Executivo do MDL}

Órgão da Convenção-Quadro das Nações Unidas que supervisiona o funcionamento do MDL. O Conselho Executivo, formado por membros representantes dos países integrantes do Protocolo, credencia as Entidades Operacionais Designadas e emite os certificados para os 
projetos que cumprem todas as etapas previstas no MDL.

\section{Entidade Operacional Designada (EOD)}

Entidade qualificada pela Conferência das Partes, por recomendação do Conselho Executivo do MDL, para validar projetos de MDL propostos ou verificar e certificar reduções de GEEs resultantes do projeto. Para atuar no Brasil, a EOD deve, adicionalmente, ser reconhecida pela Autoridade Nacional Designada e estar plenamente estabelecida no País.

\section{Autoridade Nacional Designada (AND)}

Entidade governamental de um país por este formalmente indicada para revisar e conferir a aprovação nacional dos projetos propostos em seu território, no âmbito do MDL. Essa aprovação constitui um dos requisitos para que o projeto seja encaminhado ao Conselho Executivo do MDL. No Brasil, a AND é a Comissão Interministerial de Mudanças Globais do Clima, constituída por representantes dos seguintes ministérios: Ciência e Tecnologia (coordenador da Comissão); Relações Exteriores; Agricultura, Pecuária e Abastecimento; Transportes; Minas e Energia; Planejamento, Orçamento e Gestão; Meio Ambiente; Desenvolvimento, Indústria e Comércio Exterior; Cidades; Fazenda; e Casa Civil da Presidência da República.

\section{Registro do projeto no Conselho Executivo}

$\mathrm{O}$ registro representa a aceitação ou o reconhecimento formal de um projeto, por parte do Conselho Executivo, como projeto de MDL.

\section{Redução Certificada de Emissão (RCE)}

Mercado gerado pelas transações de compra e venda de RCE, que poderá ser adquirida, inclusive, por empresas, situadas em países do Anexo I, com o objetivo de abater suas metas de redução de emissões. A RCE é uma unidade emitida pelo Conselho Executivo do MDL(ONU), em decorrência da atividade de um projeto de MDL. Representa a remoção ou a nãoemissão de uma tonelada métrica equivalente de dióxido de carbono pelo empreendimento.

\section{Mercado Brasileiro de Redução de Emissões (MBRE)}

Corresponde ao conjunto de instituições, regulamentações, sistemas de registro de projetos e centro de negociação em processo de implementação no Brasil, pela BM\&F/BVRJ (Bolsa de Mercadorias \& Futuros/Bolsa de Valores do Rio de Janeiro), em convênio com o Ministério do Desenvolvimento, Indústria e Comércio Exterior (MDIC), visando estimular o desenvolvimento de projetos de MDL e viabilizar negócios no mercado ambiental de forma organizada e transparente. A BM\&F fornece aos participantes desse mercado um banco de projetos de MDL . Em breve, colocará à disposição destes um ambiente organizado para a negociação de redução de emissões.

\section{Banco de projetos da Bolsa de Mercadorias \& Futuros (BM\&F)}

Sistema eletrônico para registro de informações relacionadas a projetos de MDL que já tenham sido validados por uma EOD ou que ainda estejam em fase de estruturação. Além disso, investidores qualificados - e précadastrados pela Bolsa - poderão divulgar suas intenções em adquirir no mercado créditos a serem gerados por projetos de MDL.

\section{Etapas de um Projeto de MDL}

Antes de iniciar a elaboração de um projeto de MDL, seu proponente deve observar que, de acordo com as regras estabelecidas nas COPs (Conferências das Partes), a participação em um projeto de MDL deve ser voluntária (ou seja, não são aceitos projetos induzidos ou desenvolvidos em decorrência de legislação governamental que retirea natureza espontânea do empreendimento).

A Figura 1, mostra as diferentes etapas que um projeto deve cumprir para receber os RCE's no âmbito do MDL. 


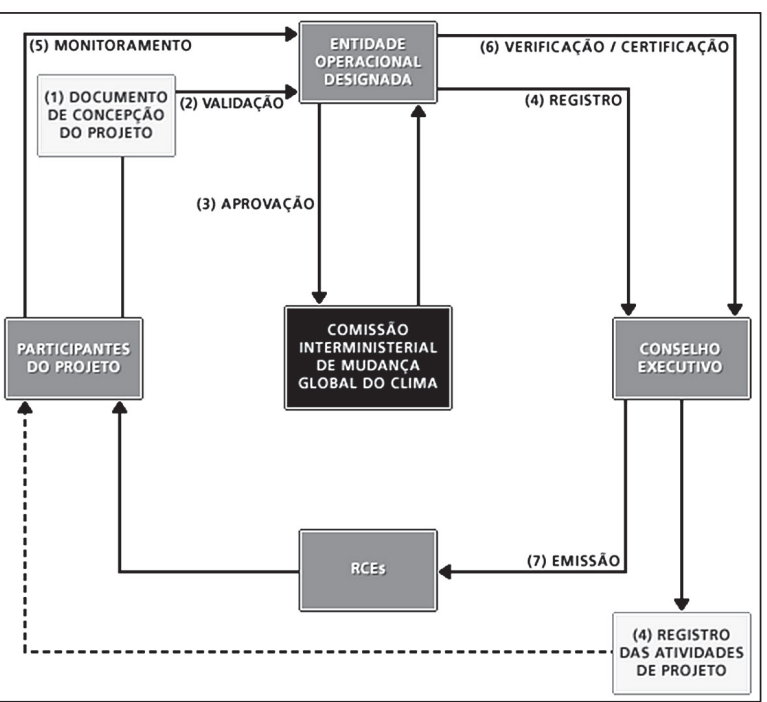

Fonte: BVRJ (2006).

FIGURA 1 - Ciclo de um projeto de MDL.

\section{Etapa 1 - Concepção do Projeto}

$\mathrm{Na}$ fase de concepção do projeto (etapa 1 da Figura 1), além da metodologia de monitoramento que deve ser utilizada para verificar o cumprimento das metas de redução de emissões e/ou de remoção de $\mathrm{CO}_{2}$ equivalente $\left(\mathrm{CO}_{2} \mathrm{e}\right)$, é necessário que o proponente (o desenvolvedor do projeto) estabeleça a adicionalidade e a linha de base do projeto. Com relação ao primeiro, as atividades de um projeto de MDL serão consideradas adicionais se as emissões antropogênicas de $\mathrm{CO}_{2}$ e forem menores do que as que ocorreriam na ausência do projeto de MDL e/ou se a remoção de $\mathrm{CO}_{2} \mathrm{e}$ (da atmosfera) for superior àquela que ocorreria na ausência do projeto de MDL. Por sua vez, a linha de base de um projeto de MDL constitui o cenário representativo das emissões/remoções antropogênicas de $\mathrm{CO}_{2} \mathrm{e}$ que ocorreriam na ausência do projeto (BVRJ, 2007).

Para auxiliar as Partes (países) na apresentação de tais informações, o Conselho Executivo do MDL elaborou o documentobase denominado Documento de Concepção do Projeto (DCP), que vem a ser, efetivamente, a forma-padrão de apresentação e encaminhamento de projetos que busquem habilitação à condição de MDL. Os responsáveis por essa etapa do processo são os participantes do projeto (AGÊNCIA CT, 2006).

Em seguida, o participante do projeto deve contratar uma empresa especializada independente (Entidade Operacional Designada ou EOD), devidamente reconhecida pelo Conselho Executivo, para revisar (validar) o documento e analisar outras informações relevantes, como comentários das partes interessadas e possíveis impactos sócioambientais decorrentes da implantação do projeto (BVRJ, 2007).

\section{Etapa 2 - Validação}

A validação (etapa 2 da Figura 1) é o processo deavaliação independentedeumprojeto de MDL, por parte de uma EOD, no tocante aos requisitos próprios desse mecanismo, conforme estabelecido na Decisão 17/CP.7 e nas decisões pertinentes da COP, com base no Documento de Concepção do Projeto. O objetivo primário da validação é assegurar que todos os critérios pertinentes foram atendidos (BVRJ, 2007 e AGÊNCIA CT, 2006).

De acordo com a Resolução $\mathrm{n}^{\circ} 1$ do Conselho Interministerial de Mudança Global do Clima, a EOD selecionada pelos participantes do projeto para executar a validação deve revisar o DCP e qualquer documentação de apoio, confirmando o atendimento aos seguintes tópicos:

- Requisitos de participação;

- comentários dos atores locais (Prefeitura e Câmara dos vereadores, Órgãos Ambientais Estadual e Municipal, Fórum Brasileiro de ONG's e Movimentos Sociais para o Meio Ambiente e Desenvolvimento, Associações comunitárias e o Ministério Público);

- documentação sobre análise dos impactos ambientais;

- adicionalidade do projeto;

- metodologias de linha de base e monitoramento;

- conformidade com demais requisitos do MDL.

A Figura 2 mostra sucintamente como 
funciona o processo de validação de um projeto de MDL.

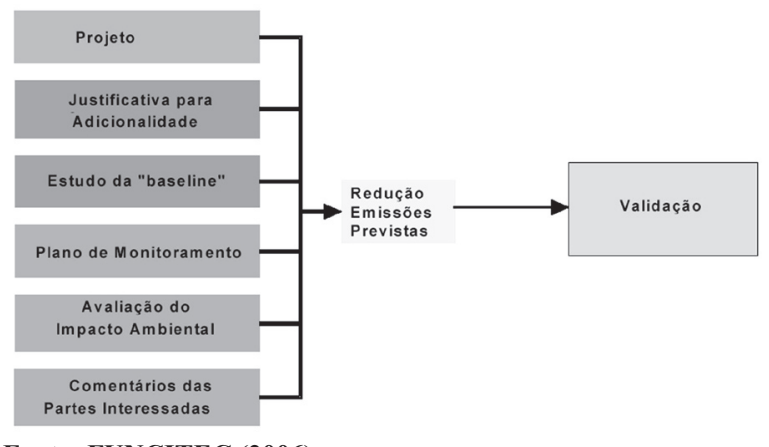

Fonte: FUNCITEC (2006).

FIGURA 2 - Processo de Validação.

\section{Etapa 3 - Aprovação}

A aprovação (etapa 3 da Figura 1) do projeto de MDL no país hospedeiro é efetuada pela Autoridade Nacional Designada (AND), e corresponde à aceitação da atividade do projeto de MDL pelo governo local. No Brasil, a AND é a Comissão Interministerial de Mudança Global do Clima (CIMGC), que tem como atribuição verificar se os projetos estão consistentes com seu objetivo duplo: a) redução das emissões de GEE e/ou remoção de $\mathrm{CO}_{2}$ atmosférico; e b) promoção do desenvolvimento sustentável, segundo cinco critérios básicos: distribuição de renda, sustentabilidade ambiental local, desenvolvimento das condições de trabalho e geração líquida de emprego, capacitação e desenvolvimento tecnológico, e integração regional e articulação com outros setores (BVRJ, 2007 e AGÊNCIA CT, 2006).

A aprovação de projetos no Conselho Executivo do MDL é subseqüente à aprovação pela Autoridade Nacional Designada. A aprovação pela CIMGC é necessária para a continuidade dos projetos, mas não é suficiente para sua aprovação pelo Conselho Executivo, que analisa também a metodologia escolhida, a adicionalidade do projeto, entre outros aspectos (BVRJ, 2007).

\section{Etapa 4 - Registro}

Após a aprovação, o projeto segue para o registro (etapa 4 da Figura 1), que é a aceitação formal, pelo Conselho Executivo, de um projeto validado como projeto de MDL. O registro é pré-requisito para verificação, certificação e emissão das RCE's relativas a essa atividade de projeto (BVRJ, 2007 e AGÊNCIA CT, 2006).

Segundo a Resolução ${ }^{\circ} 1$ do Conselho Interministerial de Mudança Global do Clima, o registro no Conselho Executivo deve ser considerado final, oito semanas após a data de recebimento, pelo mesmo, da requisição de registro, a menos que uma Parte envolvida ou três membros do Conselho Executivo requisitem uma revisão da proposta. A revisão do Conselho Executivo deve ser feita de acordo com as seguintes disposições:

- Deve estar relacionada com questões associadas aos requisitos de validação;

- deve ser finalizada, no mais tardar, na segunda reunião após a requisição de revisão, com a decisão e as razões de tal decisão sendo comunicadas aos participantes do projeto e ao público.

\section{Etapa 5 - Monitoramento}

UmavezregistradonoConselhoExecutivo, o projeto passa para a fase de monitoramento (etapa 5 da Figura 1). Este, é a atividade de coleta de informações sobre o projeto, desempenhada por seu proponente durante a execução do empreendimento, que objetiva mensurar as emissões antrópicas de gases de efeito estufa do projeto. A consistência dos dados contidos no relatório de monitoramento deve ser verificada e certificada por uma entidade independente (Entidade Operacional Designada), para ser encaminhada ao Conselho Executivo, permitindo que as RCE's correspondentes possam ser emitidas. Esse procedimento deve seguir um plano estabelecido pela metodologia definida no projeto (BVRJ, 2007 e AGÊNCIA CT, 2006).

Um plano de monitoramento deve conter, segundo a Resolução $n^{\circ} 1$ da CIMGC:

- A coleta e o arquivamento de todos os 
dados pertinentes necessários para estimar ou medir as emissões antrópicas de gases de efeito estufa por fontes que ocorram dentro do limite do projeto durante o período de obtenção de créditos;

- a coleta e o arquivamento de todos os dados pertinentes necessários para determinar a linha de base da emissões antrópicas de gases de efeito estufa por fontes que ocorram dentro do limite do projeto durante o período de obtenção de créditos;

- a identificação de todas as fontes potenciais e a coleta e o arquivamento de dados sobre o aumento das emissões por fontes fora do limite do projeto, que seja significativo e atribuível, de forma razoável, à atividade de projeto durante o período de obtenção de créditos;

- procedimentos de garantia e controle da qualidade para o processo de monitoramento;

- procedimentos para o cálculo periódico das reduções de emissões;

- documentação de todas as etapas envolvidas nos cálculos.

\section{Etapa 6 - Verificação / Certificação}

A verificação (etapa 6 da Figura 1) é a revisão independente e periódica e a apuração ex post, efetuada pela EOD, das reduções monitoradas das emissões antrópicas de GEE que ocorreram em conseqüência de atividade registrada do projeto de $\mathrm{MDL}$ durante o período de verificação (BVRJ, 2007 e AGÊNCIA CT, 2006).

Segundo a Resolução $\mathrm{n}^{\circ} 1$ da CIMGC, a EOD deve:

- Tornar público o relatório de monitoramento;

- determinar se a documentação do projeto está de acordo com os requisitos do DCP registrado;

- conduzir inspeções no local, podendo ser realizadas entrevistas com participantes do projeto e atores locais. Pode ainda coletar medições, observar as práticas estabelecidas e realizar teste de acurácia do equipamento de monitoração;

- se for o caso, utilizar dados adicionais de outras fontes;

- rever os resultados do monitoramento e sua documentação;

- recomendar mudanças adequadas na metodologia de monitoramento;

- determinar as reduções das emissões antrópicas por fontes que não teriam ocorrido na ausência do projeto;

- identificar e informar aos participantes do projeto qualquer preocupação quanto ao desvio da atividade em relação ao estabelecido no DCP.

Finalmente, a certificação (etapa 6 da Figura 6) é a garantia, dada por escrito pela EOD, de que, durante o período de tempo especificado, certo projeto em operação atingiu as reduções das emissões antrópicas de gases de efeito estufa conforme verificado (BVRJ, 2007).

A EOD deve informar aos participantes do projeto, às Partes envolvidas e ao Conselho Executivo a sua decisão de certificação por escrito, imediatamente após a finalização do processo, e tornar público o relatório de certificação.

\section{Etapa 7 - Emissão das RCE's}

Com a certificação, torna-se possível requerer ao Comitê Executivo a emissão das RCE's (etapa 7 da Figura 1) relativas à quantidade reduzida e/ou removida de Gases de Efeito Estufa (GEEs). Essas RCE's têm validade determinada e, conforme o caso, podem ser renovadas (BVRJ, 2007 e AGÊNCIA CT, 2006).

No Brasil, a Resolução $n^{\circ} 1 / 2003$, da Comissão Interministerial de Mudança Global do Clima reproduz os princípios do MDL definidos no Protocolo de Quioto, conceituando, inclusive, a RCE como uma unidade emitida em conformidade com oArtigo 12 doProtocolo, igual a uma tonelada métrica equivalente de dióxido 
de carbono $\left(\mathrm{tCO}_{2} \mathrm{e}\right)$, calculada com o uso dos potenciais de aquecimento global definidos na Decisão 2/CP.3 ou revisados subseqüentemente nos termos do Artigo 5 do Protocolo de Quioto. Os procedimentos para encaminhamento de projetos à Comissão Interministerial também estão definidos na Resolução n ${ }^{\circ}$ 1/2003 (BVRJ, 2007).

Na Figura 3 é apresentada a situação atual dos projetos de MDL no Brasil, com relação às etapas em que se encontram.

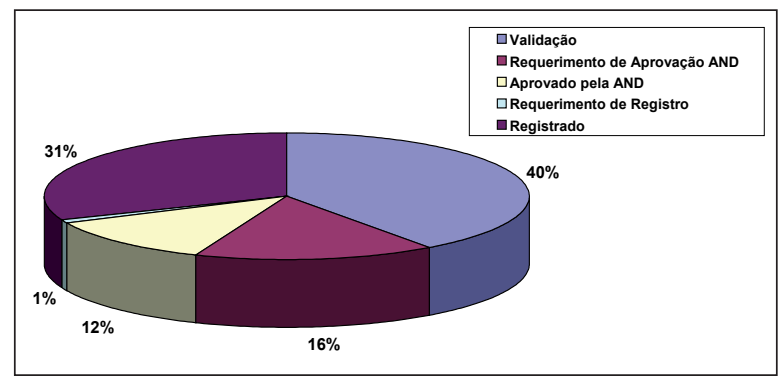

Fonte: CUNHA (2006).

FIGURA 3 - Situação dos projetos de MDL no Brasil, com relação às etapas em que se encontram.

\section{Custos dos projetos de MDL}

Os custos de um projeto de MDL incluem não só aqueles inerentes ao projeto, mas também todos os outros relacionados às transações durante a vigência do mesmo (PEMBINA, 2003).

\section{Custos do projeto propriamente dito}

Segundo (PEMBINA, 2003), os custos do projeto incluem as seguintes categorias: Custos de concepção do projeto, incluindo estudos de engenharia e análise financeira;

- custo do capital, ou se o projeto atualiza um sistema já existente, o incremento de custo do capital incorporado pela opção de se adotar um mecanismo de baixa emissão em cima de uma tecnologia de linha de base. Projetos de desenvolvimento que requerem a criação de infra-estrutura incorrerão em outros custos de capital, como obtenção de terra, materiais de construção, equipamentos e licenças de construção. Em alguns casos, o custo inicial de uma tecnologia mais eficiente pode ser mais alto que o custo da linha base;

- custos de combustível e operacionais, ou aumento ou diminuição líquida em combustível ou custos operacionais em cima da tecnologia de linha base. Dependendo da tecnologia aplicada, alguns projetos de MDL podem ficar mais caros ou mais baratos de se operar. Por exemplo, a captura de gás de aterro de lixo representa um aumento em custos operacionais para donos de aterro de lixo se a linha base simplesmente fosse a liberação do gás na atmosfera. Por outro lado, o uso "in loco" do gás para geração de eletricidade pode compensar alguns custos de combustível;

- o custo de remoção da barreira de mercado para alcançar alta penetração de mercado em um mercado distribuído. Isto normalmente se aplica a projetos de eficiência de energia que ocorrem em locais múltiplos e com grande número de consumidores. O projeto pode requerer, provendo uma contribuição direta para a tecnologia de um consumidor trazer a taxa de retorno do consumidor a um nível aceitável.

Nem todos os projetos envolverão custos em todas as categorias. Em geral, todos os projetos apresentarão custos de concepção e de transação. Alguns projetos, porém, não envolvem a construção de uma facilidade, mas, ao invés, a promoção de um dispositivo de economia de energia, como iluminação eficiente, por exemplo. Em tais casos, os custos de capital podem ser mínimos, mas o projeto incorrerá, por outro lado em custos de remoção de barreira de mercado.

\section{Custos das transações}

Adicionalmente aos custos do projeto de MDL, podem ocorrer as seguintes variedades de custos de transações, segundo PEMBINA (2003):

A) Durante a concepção do projeto:

- Seleção de metodologia de linha base e 
estimação de reduções de emissões;

- preparação de um acordo de compra de

\section{RCE's;}

- aprovação do país anfitrião e avaliação ambiental;

- preparação do Documento de Concepção do Projeto (PCP);

- requerimento de validação por uma Entidade Operacional Designada.

b) Validação por uma EOD.

c) Registro do projeto de MDL
- Taxa de registro.

d) Certificação

- Medida de redução de emissões;

- taxa de adaptação: 2\% das vendas de RCE's ficam retidos pelo Conselho Executivo, para envio aos países detentores de projetos de MDL mais afetados pelas mudanças climáticas globais.

A Figura 4 mostra um ciclo geral para projetos de MDL e seus custos de transações associados.

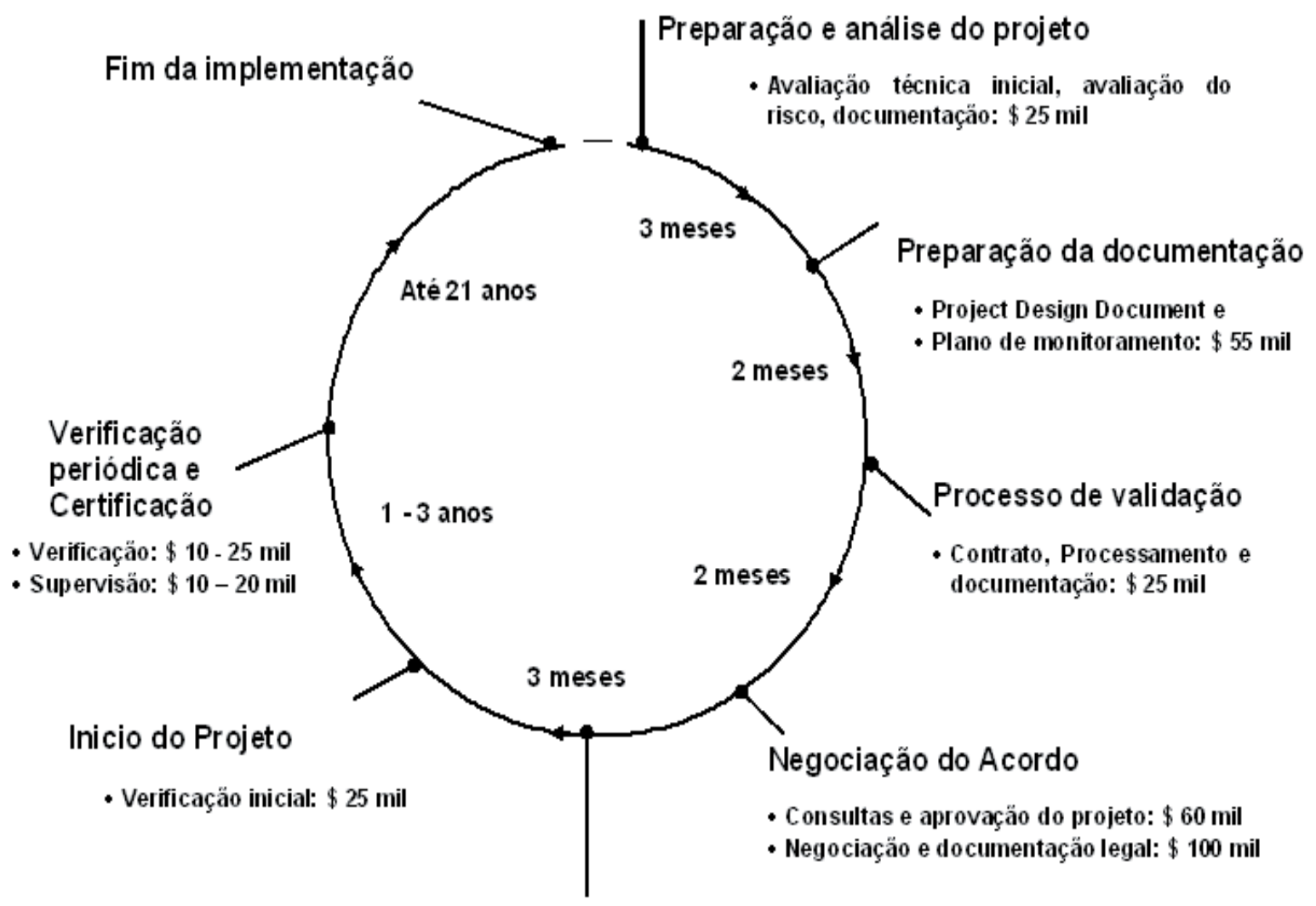

Total: \$ $265 \mathrm{mil}$

Fonte: CUNHA (2006).

FIGURA 4 - Ciclo geral de um projeto de MDL com os custos de transações associados.

Consulta a governos locais para aprovação de país anfitrião, apesar de não representar grandes custos monetários, pode representar um custo significativo de tempo, e isso deve ser considerado na fase de desenvolvimento de projeto. Por outro lado, o monitoramento e a verificação de reduções de emissões representam um custo significante. Por ser o MDL relativamente novo, é difícil de se calcular exatamente este custo, porém, estima- 
se que pode representar até $10 \%$ dos custos de transação (PEMBINA, 2003).

$\mathrm{Na}$ Tabela 1 são apresentadas as estimativas de custos para projetos de MDL de pequena e não pequena escala (grande escala).

TABELA 1. Estimativas de custos para projetos de MDL de pequena escala (SSC) e de não pequena escala (Não-SSC).

\begin{tabular}{|l|r|r|}
\hline & \multicolumn{2}{|r|}{ Custo estimado - US\$ } \\
\hline & Não-SSC & SSC \\
\hline ìtem de custo & Proj. MDL & Proj. MDL \\
\hline \hline Identificação e desenvolvimento do PIN & 20.000 & 15.000 \\
\hline Linha de base e plano de monitoramento & 20.000 & 5.000 \\
\hline Preparação do PDD & 25.000 & 20.000 \\
\hline Consultas aos Stakeholders e aprovação pela DOE & 10.000 & 7.000 \\
\hline Validação pela Entidade Operacional & 30.000 & 8.000 \\
\hline Taxa de registro & 30.000 & 5.000 \\
\hline Transação, negociação e contratação & 20.000 & 15.000 \\
\hline Monitoramento (periódico) & variável & variável \\
\hline Verificação pela entidade operacional e certificação & 15.000 & 5.000 \\
\hline Verificação periódica & 10.000 & 5.000 \\
\hline Total aproximado: & $>180.000$ & $>85.000$ \\
\hline Custos estimados que podem variar consideravelmente. & & \\
\hline
\end{tabular}

Custos estimados que podem variar consideravelmente.

Fonte: VITAE CIVILIS (2006).

Projetos de MDL também incorrerão em custos contratuais, ou legais, arranjos que normalmente não são encontrados em outros projetos de desenvolvimento. Por exemplo, um corretor, ou intermediário, pode ser exigido para facilitar a transação de projeto ou um acordo de compra de RCE's. Outras taxas legais relacionadas também podem se aplicar ao MDL (PEMBINA, 2003).

Em geral, custos de transação de grandes projetos de MDL alcançam valores de $\$ 200.000$. Porém, há previsão de que os processos de aprovação para projetos de
MDL em pequena escala serão simplificados ou eliminados, reduzindo os custos de transação significativamente para os mesmos (PEMBINA, 2003). Por enquanto, segundo Vitae Civilis (2006), uma possível solução seria o "empacotamento" de projetos de pequena escala, que sejam semelhantes. Com tal procedimento, os projetos poderiam passar por diversas etapas conjuntamente, dividindo os custos (equivalentes a apenas um projeto) entre si.

Como se pode ver na Tabela 2, quanto maiores os projetos, menores os custos de transação por tonelada de $\mathrm{CO}_{2}$. 
Tabela 2 - Tamanho dos projetos relacionado aos custos de transação.

\begin{tabular}{|cc|}
\hline Tamanho & $\left.\begin{array}{c}\text { Custos de Transação } \\
(€ / \text { t CO }\end{array}\right)$ \\
Muito grande & 0,1 \\
Grande & $0,3-1$ \\
\hline Pequeno & 10 \\
\hline Mini & 100 \\
\hline Micro & 1.000 \\
\hline
\end{tabular}

Fonte: adaptado de VITAE CIVILIS (2006).

Ainda, segundo Vitae Civilis (2006), independentemente do tamanho do projeto, o programa de "Joint Implementation" e MDL austríaco apresentou custos de transações variando entre $€ 30.000$ e $€ 100.000$. Estes valores variaram de acordo com o tipo de projeto e com as condições de "contorno" no país hospedeiro.

\section{CONSIDERAÇÕES FINAIS}

- Desde a sua concepção até o recebimento das Reduções Certificadas de Emissão (RCE's), um projeto de MDL deverá cumprir basicamente sete etapas definidas de acordo com as normas padronizadas. Essas etapas são mundialmente estabelecidas pelo Conselho Executivo do MDL, formado por membros de todos os países envolvidos no Protocolo de Quioto.

- Os custos para os requerentes das RCE's estão presentes em todas as etapas do processo sendo variáveis de acordo com a finalidade e o porte do projeto. Além dos custos monetários, os custos com o tempo envolvido em cada etapa devem ser também contabilizados.

- Projetos de MDL de pequena escala podem apresentar, relativamente, altos custos que os tornariam inviáveis economicamente, sendo necessária a utilização de "empacotamentos" ou de simplificações nas etapas deste tipo de projeto.

\section{REFERÊNCIAS BIBLIOGRÁFICAS}

Agência CT-Ministério da Ciência e Tecnologia - Projetos de MDL. Disponível em: <http:// www.agenciact.mct.gov.br/index.php/content/ view/.html >

Acesso em: 18. jan. 2007

BOLSA DE VALORES DO RIO DE JANEIRO - BVRJ . Mercado Brasileiro de Reduções de Emissões - MBRE. Perguntas freqüentes. Disponível em: < http://www.bvrj.com.br/mbre/ faq/faq.asp\#8 $>$

Acesso em: 23. jan. 2007.

BOLSA DE VALORES DO RIO DE JANEIRO - BVRJ . Mercado Brasileiro de Reduções de Emissões - MBRE. Mecanismo de desenvolvimento limpo - MDL. Disponível em:

BVRJ B < http://www.bvrj.com.br/mbre/ mecanismo/mecanismo.asp - Bolsa de Valores do Rio de Janeiro > Acesso em: 18. jan. 2007.

CENTRO DE ESTUDOS AVANÇADOS EM ECONOMIAAPLICADA-CEPEA. Estatística e Informações Sobre o Mercado de Carbono, Fevereiro de 2005. Disponível em: < http: // www.cepea.esalq.usp.br/economiaambiental/ files/2005/02fev.pdf $>$

Acesso em: 11. jan. 2007.

CUNHA, B.K. WALTER, A. FERNANDES, F. Estado de Implementação do Mecanismo de Desenvolvimento Limpo no Brasil. PCH Notícias \& SHP news, Itajubá - MG, Ano 8, Revista no 29, mar/abr/mai - 2006, pg. 16-19.

DET NORSKE VERITAS - DNV. Créditos de carbono - Validadora/verificadora. Disponível em: < www.funcitec.rct-sc.br/dnv.pdf $>$ Acesso em: 15. jan. 2007.

INSTITUTO EUVALDO LODI-IEL; CONFEDERAÇÃO NACIONAL DA 
AGRICULTURA-CNA; SERVIÇO BRASILEIRO DE APOIO ÀS MICRO E PEQUENAS EMPRESAS-SEBRAE. Estudo sobre a eficiência econômica e competitividade da cadeia agroindustrial da pecuária de corte no Brasil. Brasília: IEL/CNA/SEBRAE, 2000. 403p.

MENEGUEllo, L. A.; CAStro, M. C. A. A. de. O Protocolo de Kyoto e a geração de energia elétrica pela biomassa da cana-de-açúcar como mecanismo de desenvolvimento limpo. Revista Interações (Campo Grande), Campo Grande, v. 8, n. 1, mar. 2007.

MINISTÉRIO DA CIÊNCIA E TECNOLOGIA. - MCT. Créditos de Carbono. Brasília, 2002, 53 p. (Relatórios de Referência). Disponível em:

$<$ http://agenciact.mct.gov.br/index.php/content/ view/40685.html >

Acesso em: 18. jan. 2007.

MINISTÉRIO DA CIÊNCIA E TECNOLOGIA. - MCT. Resolução n⿳0 1 de 11 de setembro de
2003. Comissão Interministerial de Mudança Global do Clima.

Disponível em: < http://www.mct.gov.br/clima/ cigmc/pdf/Resolução01p.pdf. >

Acesso em: 07. fev. 2007.

MOREIRA, H. M.; GIOMETTI, A. B. R.. Protocolo de Quioto e as possibilidades de inserção do Brasil no Mecanismo de Desenvolvimento Limpo por meio de projetos em energia limpa. Revista Contexto internacional., Rio de Janeiro, v. 30, n. 1, abr. 2008 .

PEMBINA INSTITUTE FOR APPROPRIATE DEVELOPMENT. A user's guide to the CDM (Clean Development Mechanism), second edition, february 2003. Disponível em: < http:// www.pembina.org/pubs/pub.php?id=148 > Acesso em: 10. jan. 2007.

VITAE CIVILIS - Desenvolvimento meio ambiente e paz - Projetos de MDL. Disponível em: <http:// www.vitaecivilis.org.br/ > Acesso em: 19. jan. 2007. 